Research Article

\title{
Primary Cutaneous Lymphomas in Thailand: A 10-Year Retrospective Study
}

\author{
Chutipon Pruksaeakanan $\left(\mathbb{D},{ }^{1}\right.$ Phurichaya Teyateeti $(D), 2$ Poramin Patthamalai $\left(\mathbb{D},{ }^{1}\right.$ \\ Janista Thumrongtharadol $\mathbb{D}^{\mathrm{D}},{ }^{1}$ and Manasmon Chairatchaneeboon $\left.{ }^{1}\right)^{1}$
}

${ }^{1}$ Department of Dermatology, Faculty of Medicine Siriraj Hospital, Mahidol University, Bangkok 10700, Thailand

${ }^{2}$ Chulabhorn Hospital, HRH Princess Chulabhorn College of Medical Science, Chulabhorn Royal Academy, Bangkok 10210, Thailand

Correspondence should be addressed to Manasmon Chairatchaneeboon; mallydoc@hotmail.com

Received 27 April 2021; Accepted 24 May 2021; Published 14 June 2021

Academic Editor: Arjen F. Nikkels

Copyright (c) 2021 Chutipon Pruksaeakanan et al. This is an open access article distributed under the Creative Commons Attribution License, which permits unrestricted use, distribution, and reproduction in any medium, provided the original work is properly cited.

\begin{abstract}
Background. Primary cutaneous lymphomas (PCLs) refer to cutaneous lymphomas that primarily develop in the skin with no evidence of extracutaneous disease at the time of diagnosis. The epidemiological and clinical data of PCLs in Thailand are lacking. Objectives. To evaluate the frequency, demographic data, and clinical characteristics of different subtypes of PCLs in a tertiary care university hospital. Methods. In total, 137 patients with PCLs diagnosed in our hospital in 2008-2017 were retrospectively reviewed. Results. Of the 137 patients, $57(41.6 \%)$ were male and 80 (58.4\%) were female $(\mathrm{M}: \mathrm{F}=1: 1.4)$. The median age at diagnosis was 40 years. Most patients (134, 97.8\%) had cutaneous T-cell lymphomas (CTCLs). Three patients (2.2\%) had cutaneous B-cell lymphomas (CBCLs). The most common subtype was mycosis fungoides (MF) (67.9\%), followed by subcutaneous panniculitis-like T-cell lymphoma (SPTCL) (21.2\%), primary cutaneous anaplastic large cell lymphoma (pcALCL) (3.6\%), lymphomatoid papulosis (LyP) (1.5\%), primary cutaneous gamma/delta T-cell lymphoma (pcGDTCL) (1.5\%), Sézary syndrome (SS) (0.7\%), extranodal NK/T-cell lymphoma, nasal type (ENKTCL-NT) (0.7\%), primary cutaneous peripheral T-cell lymphoma, not otherwise specified (pcPTCL-NOS) (0.7\%), primary cutaneous diffuse large B-cell lymphoma, leg type (pcDLBCL-LT) (1.5\%), and primary cutaneous follicle center lymphoma (pcFCL) (0.7\%). Most patients with MF presented with early-stage disease (84.0\%), with hypopigmented MF the most common variant (42.6\%). Conclusions. Compared to earlier Caucasian and Asian studies, the present study revealed a higher proportion of CTCL patients with a younger age at onset and a female predominance. MF was the most common CTCL subtype, followed by SPTCL. More than $80 \%$ of MF patients were diagnosed at an early stage.
\end{abstract}

\section{Introduction}

Primary cutaneous lymphomas (PCLs) are rare disorders, which refer to a group of extranodal non-Hodgkin lymphomas (NHLs) that primarily occur in the skin without evidence of extracutaneous disease at the time of diagnosis [1]. PCLs are the second most common extranodal NHLs after gastrointestinal lymphomas [2]. The estimated annual incidence of PCLs is approximately $1: 100,000[2,3]$. According to the World Health Organization-European Organization for Research and Treatment of Cancer (WHO-EORTC) classification for cutaneous lymphomas published in 2005 and updated in 2018, PCLs can be divided into 2 main categories: cutaneous T-cell lymphomas (CTCLs) and cutaneous B-cell lymphomas (CBCLs) [1, 4]. PCLs may resemble their nodal counterparts in clinical and immunohistopathological findings, but differ in terms of their clinical course, management, and prognosis. They tend to have a more indolent course and better prognosis for the most part. Therefore, the differentiation between primary and secondary cutaneous NHLs is extremely important.

CTCLs are the most common subtype of PCLs accounting for $75-80 \%$ of PCLs $[1,4]$. Mycosis fungoides (MF) is the most common subtype, constituting $47-62 \%$ of CTCLs 
$[4,5]$. Other subtypes of CTCLs vary among nationalities and geographical areas, such as subcutaneous panniculitis-like $\mathrm{T}$ cell lymphoma (SPTCL), which is quite rare among Caucasian populations $[6,7]$ but more common in Asian populations $[8,9]$.

CBCLs account for $20-25 \%$ of PCLs in Western countries. There are 3 main subtypes of primary cutaneous Bcell lymphomas: primary cutaneous follicle center lymphoma (pcFCL), primary cutaneous marginal zone lymphoma (pcMZL), and primary cutaneous diffuse large B-cell lymphoma, leg type (pcDLBCL-LT). The prevalence of CBCLs is relatively lower in Asian compared to Western populations $[6,8-10]$.

Currently, epidemiological and clinical data of PCLs in Southeast Asia remain sparse and indeed have not been previously reported in Thailand. Therefore, we aimed to study the frequency and demographic and clinical characteristics of the different subtypes of PCLs in our center, a tertiary care university hospital in Thailand.

\section{Methods}

This retrospective study was conducted at the Faculty of Medicine, Siriraj Hospital, Mahidol University. Patients diagnosed with cutaneous lymphomas from January 2008 to December 2017 were included. Patients with a history of extracutaneous lymphoma at the time of diagnosis or an incomplete history in the medical records were excluded. The diagnosis of PCLs was confirmed clinically and immunohistopathologically according to the WHO-EORTC classification for cutaneous lymphomas $[1,4]$. Clinical stages and TNMB classification of patients with MF and Sézary syndrome (SS) were identified using the International Society for Cutaneous Lymphomas (ISCL) and the EORTC proposal in 2007, which was modified in 2011 [11, 12].

Data collection was performed by a review of the hospital electronic medical records. Demographic data and clinical characteristics, including age at diagnosis, sex, morphology, anatomical site of the lesions, TNMB classification and stage, and nodal and extracutaneous involvement, were recorded. This study was approved by the Siriraj Institutional Review Board ethics committee (Si 229/2019).

\section{Results}

We identified a total of 137 patients diagnosed with PCLs from 2008 to 2017. Table 1 summarizes the demographic data and clinical characteristics of the PCL patients in our study. There were 57 (41.6\%) males and 80 (58.4\%) females, exhibiting a female predominance $(\mathrm{M}: \mathrm{F}=1: 1.4)$. The median age at disease onset was 35 years (range $1-80$ years). The median age at diagnosis was 40 years (range $1-83$ years). CTCLs were the most common group of PCLs, comprising $134(97.8 \%)$ patients, whereas only $3(2.2 \%)$ patients were diagnosed with CBCLs. MF was the most common CTCL subtype, accounting for $67.9 \%$ of PCLs. Interestingly, SPTCL was the second most common CTCL subtype (21.2\%), followed by pcALCL (3.6\%). Regarding CBCL patients, 2 patients had pcDLBCL-LT and another one had pcFCL.
In MF/SS, the most common subtype of PCLs, there were $93 \mathrm{MF}$ patients and 1 SS patient. Of these 94 patients, 39 $(41.5 \%)$ were male and 55 (58.5\%) were female $(\mathrm{M}: \mathrm{F}=1: 1.4)$. The median age at disease onset was 34.5 years (range 1-80 years) and the median age at diagnosis was 40 years (range 1-83 years). Figure 1 summarizes the clinical stages of the patients. In total, $79(84.0 \%)$ patients were diagnosed with early-stage MF (stage IA-IIA).

The clinical characteristics by clinicopathological variants of patients with MF/SS are summarized in Table 2. The most common MF variant was hypopigmented $\mathrm{MF}$ (HMF), which accounted for $42.6 \%$ of cases. A female predominance was observed in classical, HMF, and folliculotropic MF (FMF), whereas poikilodermatous and erythrodermic MF occurred without gender predilection. The median age at the onset of symptoms and at diagnosis was younger in the hypopigmented $(21.5,28$ years) and poikilodermatous variants $(24,39$ years). All patients with HMF had only patch lesions. The most common sites of involvement were the trunk and lower extremities (79.8\%), followed by the upper extremities (72.3\%). Lesions on the head and neck were observed in $19.1 \%$ of cases, most frequently in patients with FMF subtype.

Among the 29 patients with SPTCL, the second most common subtype, 11 (37.9\%) were male and 18 (62.1\%) were female $(\mathrm{M}: \mathrm{F}=1: 1.6)$. The median age of disease onset was 31 years (range $9-61$ years). The median age at diagnosis was also 31 years (range 11-61 years). Most patients presented with nodules $(79.3 \%)$, followed by plaques $(24.1 \%)$ and patches $(3.4 \%)$. The most common sites of involvement were the trunk and extremities (Table 3 ). In our study, the most common extracutaneous manifestations reported in SPTCL patients were B-symptoms (86.2\%). Laboratory abnormalities included elevated LDH (82.8\%), anemia (72.4\%), leukopenia (65.5\%), and elevated liver enzymes (55.2\%). Four patients (13.8\%) had hemophagocytic syndrome (HPS) or hemophagocytic lymphohistiocytosis (HLH).

\section{Discussion}

To date, only limited studies have reported on the epidemiology and clinical characteristics of PCLs in Southeast Asia. PCLs were recognized as the second most common extranodal NHLs after gastrointestinal lymphomas, according to most studies [2]. In 1998, researchers from Thailand reported that cutaneous lymphomas were the third most common extranodal NHLs, following upper aerodigestive tract and gastrointestinal tract [13]. However, epidemiological data on PCLs are rare and have not previously been investigated in Thailand. To the best of our knowledge, this is the first study focused on the frequency, demographic data and clinical characteristics of PCLs in Thailand. Our hospital is one of the largest tertiary care centers that accepts patient referrals from all regions of Thailand. Our study might represent the epidemiology of PCLs in Thailand. We also compared our results to previous national data from several countries and regions (Table 4).

Of the 137 PCL patients, we found that the frequency of CTCLs (97.8\%) was higher than in most previous studies 
TABLE 1: Frequency of primary cutaneous lymphomas by sex, median age at onset, and at diagnosis of the diseases.

\begin{tabular}{|c|c|c|c|c|c|c|}
\hline & $\begin{array}{c}\text { Total } N \\
\quad(\%)\end{array}$ & $\begin{array}{l}\text { Male } \\
\quad N\end{array}$ & $\begin{array}{l}\text { Female } \\
\qquad N\end{array}$ & $\begin{array}{l}M: F \\
\text { ratio }\end{array}$ & $\begin{array}{l}\text { Age at onset, median } \\
\text { (range), years }\end{array}$ & $\begin{array}{c}\text { Age at diagnosis, median } \\
\text { (range), years }\end{array}$ \\
\hline Total & $\begin{array}{c}137 \\
(100)\end{array}$ & 57 & 80 & $1: 1.4$ & $35(1-80)$ & $40(1-83)$ \\
\hline Cutaneous T-cell and NK-cell lymphomas & $\begin{array}{c}134 \\
(97.8)\end{array}$ & 56 & 78 & $1: 1.4$ & $35(1-80)$ & $39(1-83)$ \\
\hline Mycosis fungoides & $\begin{array}{c}93 \\
(67.9)\end{array}$ & 38 & 55 & $1: 1.4$ & $34(1-80)$ & $40(1-83)$ \\
\hline Sézary syndrome & $1(0.7)$ & 1 & 0 & - & $64(64)$ & $66(66)$ \\
\hline $\begin{array}{l}\text { Primary cutaneous anaplastic large cell } \\
\text { lymphoma }\end{array}$ & $5(3.6)$ & 3 & 2 & $1.5: 1$ & $51(11-66)$ & $51(11-66)$ \\
\hline Lymphomatoid papulosis & $2(1.5)$ & 1 & 1 & $1: 1$ & $52.5(42-63)$ & $52.5(42-63)$ \\
\hline $\begin{array}{l}\text { Subcutaneous panniculitis-like T-cell } \\
\text { lymphoma }\end{array}$ & $\begin{array}{c}29 \\
(21.2)\end{array}$ & 11 & 18 & $1: 1.6$ & $31(9-61)$ & $31(11-61)$ \\
\hline Extranodal NK/T-cell lymphoma, nasal type & $1(0.7)$ & 1 & 0 & - & $54(54)$ & $57(57)$ \\
\hline $\begin{array}{l}\text { Primary cutaneous gamma/delta } \mathrm{T} \text {-cell } \\
\text { lymphoma }\end{array}$ & $2(1.5)$ & 0 & 2 & - & $41.5(13-70)$ & $42.5(13-72)$ \\
\hline $\begin{array}{l}\text { Primary cutaneous peripheral T-cell } \\
\text { lymphoma, not otherwise specified }\end{array}$ & $1(0.7)$ & 1 & 0 & - & $58(58)$ & $60(60)$ \\
\hline Cutaneous B-cell lymphomas & $3(2.2)$ & 1 & 2 & $1: 2$ & $72(67-74)$ & $72(68-74)$ \\
\hline $\begin{array}{l}\text { Primary cutaneous diffuse large B-cell } \\
\text { lymphoma, leg type }\end{array}$ & $2(1.5)$ & 1 & 1 & $1: 1$ & $69.5(67-72)$ & $70(68-72)$ \\
\hline Primary cutaneous follicle center lymphoma & $1(0.7)$ & 0 & 1 & - & $74(74)$ & $74(74)$ \\
\hline
\end{tabular}

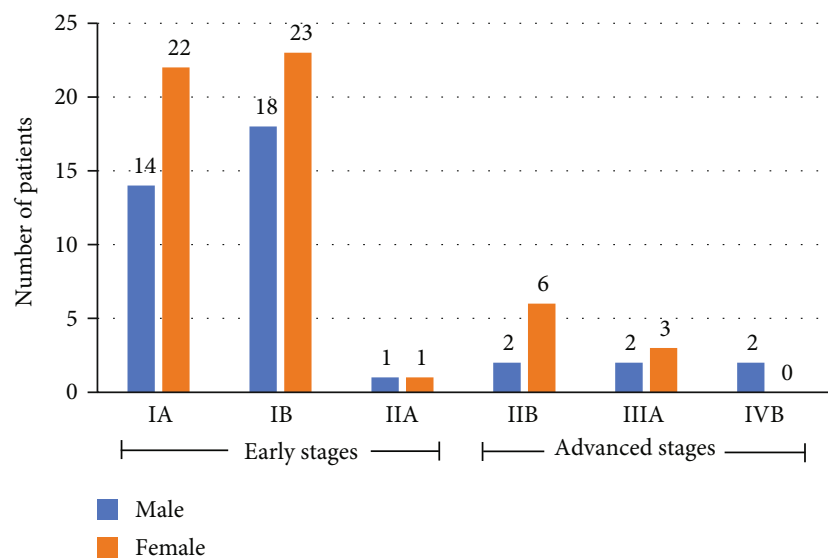

FIGURE 1: Clinical stages of 94 patients with mycosis fungoides and Sézary syndrome.

reported worldwide $[3-6,8-10,14-16]$. This finding is consistent with those reported in studies from China (94.5\%) [10], Iran (96\%) [17], Argentina (93\%) [16], and Taiwan (92.3\%) [18], but relatively higher than those from Japan (85.7\%) [8] and Korea (88\%) [9]. Our study emphasizes that non-Caucasian populations appeared to have a higher proportion of CTCLs than those of Caucasian populations (USA, 72.4\% [6]; Netherlands and Austria, 78\% [4]; Germany, 85\% [5]; Switzerland, 72\% [15]; Italy, 78.7\% [3]). In contrast, the incidence of CBCLs (2.2\%) was much lower in our study than that reported in studies from Western countries. The median age at diagnosis (40 years) of patients with PCLs overall in our study was younger than those reported in many previous studies, particularly from Western countries such as Switzerland (56 years) [15] and Italy (64 years) [3], but was close to those reported in studies from China (44.5 years) [10] and Iran (36 years) [17]. This could be explained by a high rate of HMF, a variant particularly affects young adults, in this study. However, the median age of CBCL patients (72 years) was considerably higher, compared with CTCL patients (39 years). Interestingly, we noticed a female predominance $(\mathrm{M}: \mathrm{F}=1: 1.4)$ in almost all PCL subtypes, except for pcALCL. This finding was different from most earlier studies that reported a male predominance, but similar to the studies of a female predominance from Switzerland $(\mathrm{M}: \mathrm{F}=1: 1.4)$ [15] and $\operatorname{Iran}(\mathrm{M}: \mathrm{F}=1: 1.2)$ [17].

$\mathrm{MF} / \mathrm{SS}$ was the most common subtype of CTCLs observed in our study. The median age at onset (34.5 years) and at diagnosis (40 years) were younger than those reported in Western countries (57-61 years) [19-21]. Wilson et al. postulated that the age at presentation of patients with $\mathrm{MF}$ in non-white racial populations was younger than in whites [22]. We also found that HMF was the most common MF variant with a youngest median age at diagnosis (28 years). Our findings concurred with previous studies from Singapore, which demonstrated a young age of patients at the diagnosis of MF/SS and a high frequency of HMF. However, the median age of patients with HMF in Singapore was younger than in our study, according to reports by Tan et al. (17 years) [23] and Lim et al. (26 years) [24]. Our study supports the suggestion from previous data that HMF is predilected for dark-skinned and Asian patients, and it most commonly affects young adults and children [25]. All HMF patients in this study presented with patch lesions, which correlated with their excellent prognosis. 
TABLE 2: Clinical characteristics of different variants of mycosis fungoides (MF) and Sézary syndrome (SS).

\begin{tabular}{|c|c|c|c|c|c|c|c|}
\hline & $\begin{array}{l}\text { Classical } \\
\text { MF }\end{array}$ & $\begin{array}{c}\text { Hypopigmented } \\
\text { MF }\end{array}$ & $\begin{array}{c}\text { Poikilodermatous } \\
\text { MF }\end{array}$ & $\begin{array}{c}\text { Folliculotropic } \\
\text { MF }\end{array}$ & $\begin{array}{c}\text { Erythrodermic } \\
\text { MF }\end{array}$ & $\begin{array}{l}\text { Sézary } \\
\text { syndrome }\end{array}$ & $\begin{array}{c}\text { All } \\
\mathrm{MF} / \mathrm{SS}\end{array}$ \\
\hline$N(\%)$ & $36(38.3)$ & $40(42.6)$ & $8(8.5)$ & $5(5.3)$ & $4(4.3)$ & $1(1.1)$ & $94(100)$ \\
\hline \multicolumn{8}{|l|}{ Sex } \\
\hline Male & 15 & 15 & 4 & 2 & 2 & 1 & 39 \\
\hline Female & 21 & 25 & 4 & 3 & 2 & 0 & 55 \\
\hline Male : female & $1: 1.4$ & $1: 1.7$ & $1: 1$ & $1: 1.5$ & $1: 1$ & Male & $1: 1.4$ \\
\hline \multicolumn{8}{|l|}{ Age (years) } \\
\hline Onset & 49 & 21.5 & 24 & 62 & 63 & 64 & 34.5 \\
\hline Diagnosis & 49.5 & 28 & 39 & 62 & 67 & 66 & 40 \\
\hline \multicolumn{8}{|l|}{$\begin{array}{l}\text { Morphology, } N \\
(\%)\end{array}$} \\
\hline Patch & $25(69.4)$ & $40(100)$ & $7(87.5)$ & $3(60.0)$ & $2(50.0)$ & $1(100)$ & $78(83.0)$ \\
\hline Plaque & $23(63.9)$ & $0(0)$ & $4(50.0)$ & $5(100)$ & $4(100)$ & $1(100)$ & $37(39.4)$ \\
\hline Tumor & $6(16.7)$ & $0(0)$ & $0(0)$ & $1(20.0)$ & $2(50.0)$ & $0(0)$ & $9(9.6)$ \\
\hline Ulcer & $3(8.3)$ & $0(0)$ & $0(0)$ & $0(0)$ & $0(0)$ & $0(0)$ & $3(3.2)$ \\
\hline Erythroderma & $0(0)$ & $0(0)$ & $0(0)$ & $1(20.0)$ & $4(100)$ & $1(100)$ & $6(6.4)$ \\
\hline \multicolumn{8}{|l|}{ Location, $N(\%)$} \\
\hline Head and neck & $6(16.7)$ & $3(7.5)$ & $1(12.5)$ & $4(80.0)$ & $3(75.0)$ & $1(100)$ & $18(19.1)$ \\
\hline Trunk & $30(83.3)$ & $31(77.5)$ & $8(100)$ & $1(20.0)$ & $4(100)$ & $1(100)$ & $75(79.8)$ \\
\hline $\begin{array}{c}\text { Upper } \\
\text { extremities }\end{array}$ & $29(80.6)$ & $30(75.0)$ & $4(50.0)$ & $1(20.0)$ & $4(100)$ & $1(100)$ & $68(72.3)$ \\
\hline $\begin{array}{c}\text { Lower } \\
\text { extremities }\end{array}$ & $29(80.6)$ & $34(85.0)$ & $5(62.5)$ & $2(40.0)$ & $4(100)$ & $1(100)$ & 75 (79.8) \\
\hline
\end{tabular}

TABLE 3: Morphologies and anatomical locations of primary cutaneous T-cell and B-cell lymphomas other than mycosis fungoides and Sézary syndrome.

\begin{tabular}{|c|c|c|c|c|c|c|c|c|}
\hline & \multicolumn{6}{|c|}{ Cutaneous T-cell and NK-cell lymphomas } & \multicolumn{2}{|c|}{$\overline{\text { Cutaneous B-cell lymphomas }}$} \\
\hline & $\begin{array}{l}\text { pcALCL } \\
(N=5)\end{array}$ & $\begin{array}{c}\text { LyP } \\
(N=2)\end{array}$ & $\begin{array}{c}\text { SPTCL } \\
(N=29)\end{array}$ & $\begin{array}{c}\text { ENKTCL-NT } \\
\quad(N=1)\end{array}$ & $\begin{array}{l}\text { pcGDTCL } \\
(N=2)\end{array}$ & $\begin{array}{l}\text { pcPTCL-NOS } \\
\quad(N=1)\end{array}$ & $\begin{array}{l}\text { pcDLBCL-LT } \\
\quad(N=2)\end{array}$ & $\begin{array}{l}\text { pcFCL } \\
(N=1)\end{array}$ \\
\hline \multicolumn{9}{|c|}{$\begin{array}{l}\text { Morphology, } N \\
(\%)\end{array}$} \\
\hline Patch & $0(0)$ & $0(0)$ & $1(3.4)$ & $0(0)$ & $0(0)$ & $0(0)$ & $0(0)$ & $0(0)$ \\
\hline Plaque & $0(0)$ & $0(0)$ & $7(24.1)$ & $0(0)$ & $1(50.0)$ & $0(0)$ & $1(50.0)$ & $1(100)$ \\
\hline Papule & $0(0)$ & $2(100)$ & $0(0)$ & $0(0)$ & $0(0)$ & $1(100)$ & $0(0)$ & $0(0)$ \\
\hline Nodule & $4(80.0)$ & $1(50.0)$ & $23(79.3)$ & $1(100)$ & $2(100)$ & $1(100)$ & $2(100)$ & $0(0)$ \\
\hline Ulcer & $1(20.0)$ & $2(100)$ & $0(0)$ & $1(100)$ & $1(50.0)$ & $0(0)$ & $0(0)$ & $0(0)$ \\
\hline \multicolumn{9}{|l|}{$\begin{array}{l}\text { Location, } N \\
\text { (\%) }\end{array}$} \\
\hline $\begin{array}{l}\text { Head and } \\
\text { neck }\end{array}$ & $2(40.0)$ & $1(50.0)$ & $1(3.4)$ & $0(0)$ & $1(50.0)$ & $1(100)$ & $0(0)$ & $1(100)$ \\
\hline Trunk & $4(80.0)$ & $2(100)$ & $22(75.9)$ & $0(0)$ & $2(100)$ & $1(100)$ & $1(50.0)$ & $0(0)$ \\
\hline $\begin{array}{c}\text { Upper } \\
\text { extremities }\end{array}$ & $0(0)$ & $2(100)$ & $17(58.6)$ & $1(100)$ & $1(50.0)$ & $1(100)$ & $0(0)$ & $0(0)$ \\
\hline $\begin{array}{l}\text { Lower } \\
\text { extremities }\end{array}$ & $2(40.0)$ & $1(50.0)$ & $25(86.2)$ & $0(0)$ & $2(100)$ & $1(100)$ & $1(50.0)$ & $0(0)$ \\
\hline
\end{tabular}




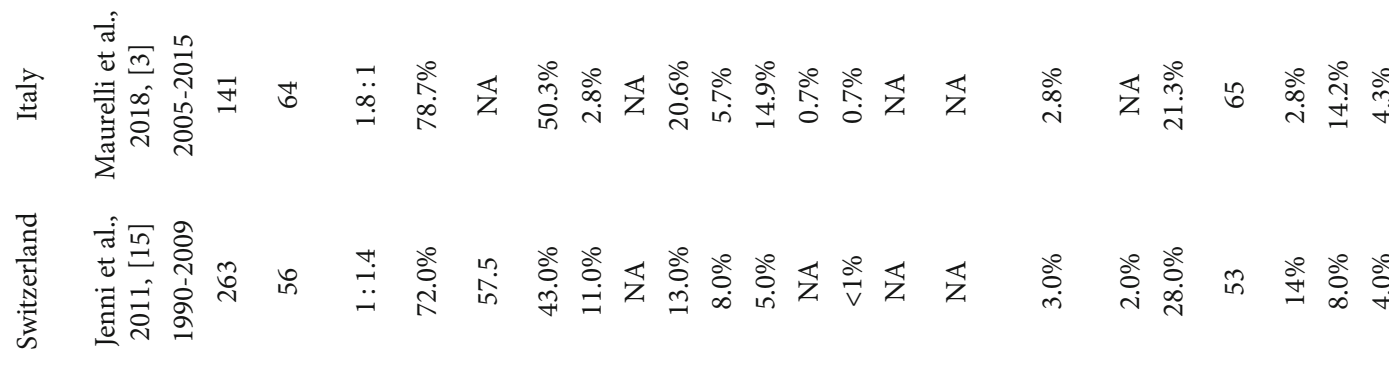

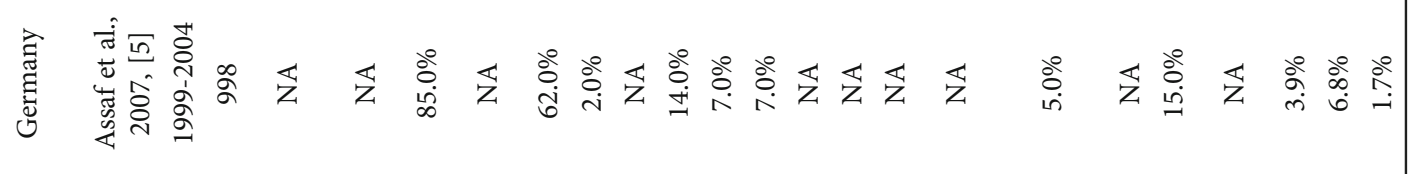

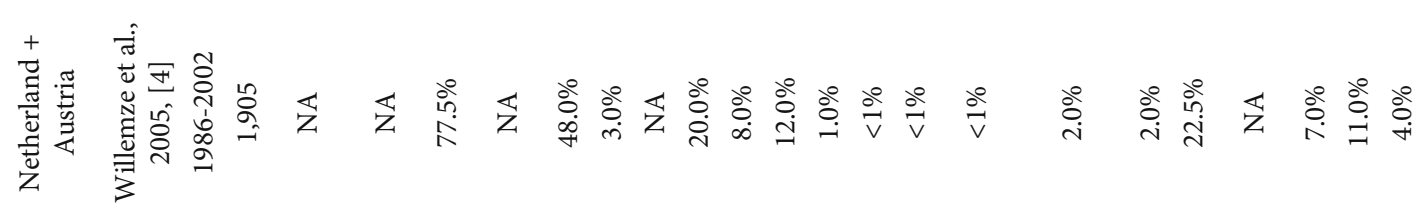

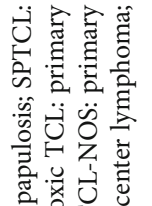

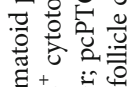

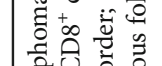

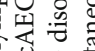

골

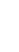

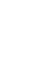

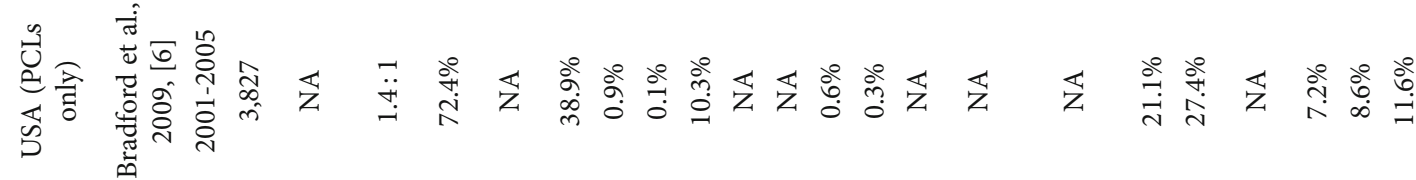

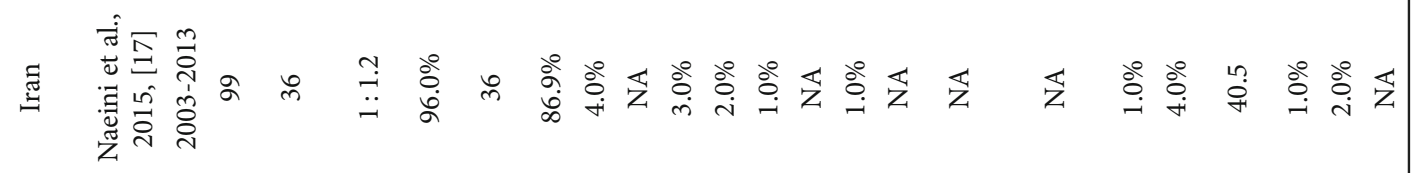

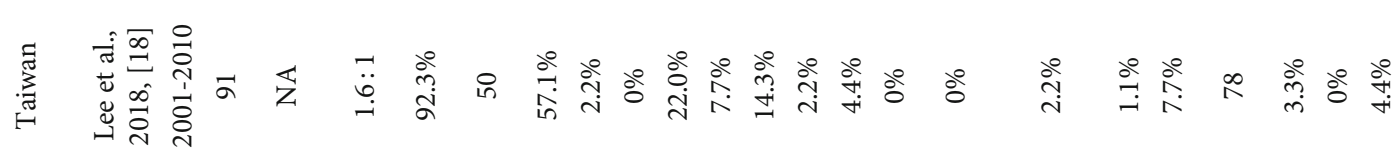

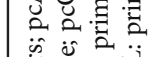

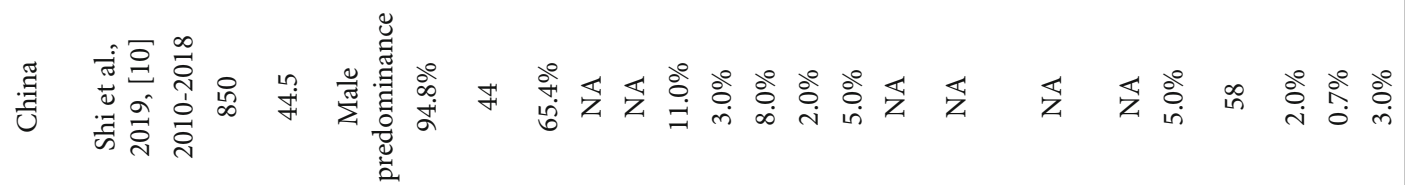
这全

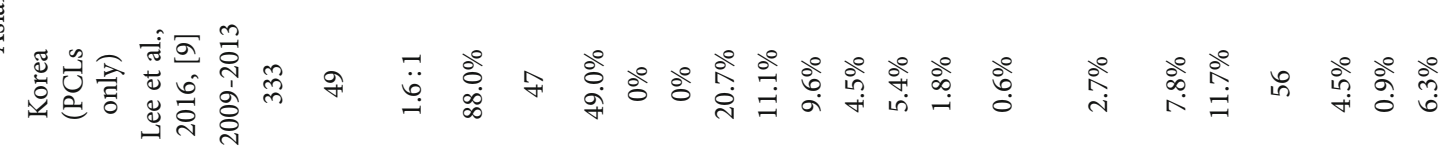

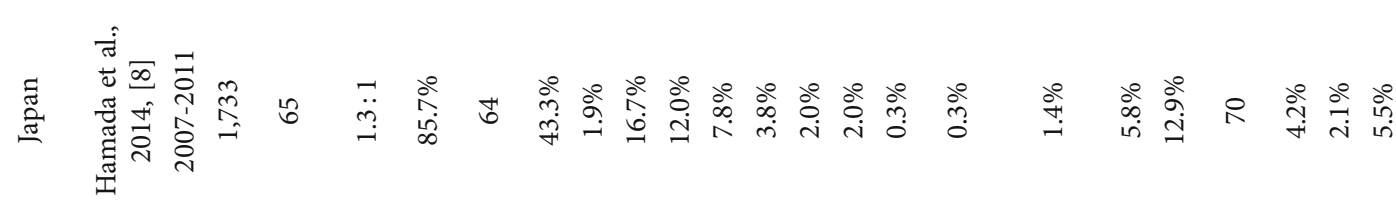

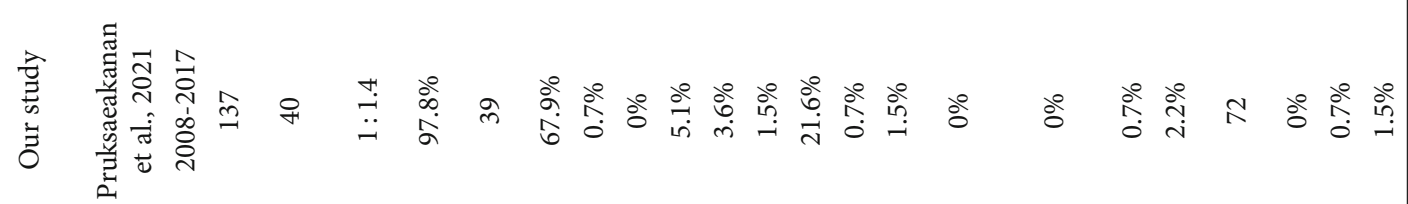

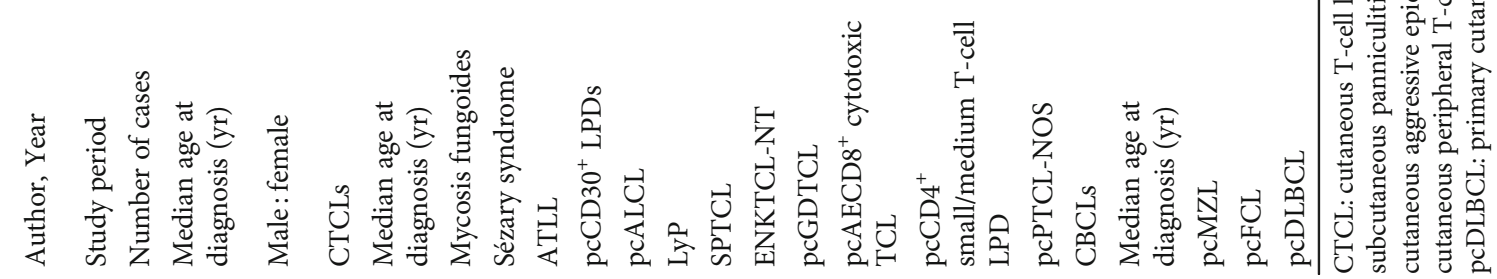


In terms of clinical staging, most MF/SS patients (84\%) in the present study were diagnosed at early-stage, similar to previous studies from several countries, for instance, Taiwan (82.6\%) [18], Iran (86.4\%) [17], and Italy (87.2\%) [3]. Early disease detection may be attributed to the development of advanced laboratory techniques, including genetics and molecular biology, and the rise in awareness among dermatologists and pathologists about PCLs in the recent years.

SPTCL is a rare subtype of CTCLs that preferentially involves subcutaneous tissue. We demonstrated that it predominantly affected young adult females with a median age at diagnosis of 31 years, similar to a previous study [26]. SPTCL constitutes approximately $1 \%$ of PCLs in Europe, but it is more common in Asia [8,9]. According to Park et al., the frequency of SPTCL in Korea was 10.4\% of PCLs [27]. Interestingly, SPTCL was the second most common subtype $(21.2 \%)$ of PCLs demonstrated in our study, which is a higher figure than we found in other studies from the literature review. An earlier study on mature T-cell and NK-cell lymphomas conducted in our hospital reported that the prevalence of SPTCL was higher than in other studies as well [28]. B-symptoms were observed in $86.2 \%$ of SPTCL patients in the present study, which was a similar rate to those reported in Thailand (87.5\%) by Rutnin et al. [29] and in Japan (81\%) by Ohtsuka et al. [30]. However, the prevalence of Bsymptoms in our study was higher than in Europe (59\%) [26]. We observed that HPS developed in $13.8 \%$ of SPTCL cases. Studies by Willemze et al. [26], Ohtsuka et al. [30], Rutnin et al. [29], and Lee et al. [31] exhibited wide variations of the HPS associated with SPTCL in Europe (17\%), Japan (45\%), Thailand (37.5\%), and Korea (14\%), respectively. In addition, laboratory abnormalities, including elevated LDH, elevated liver enzymes, anemia, and leukopenia, were observed, similar to in previous reports [26, 29, 31, 32].

The occurrence of primary cutaneous $\mathrm{CD} 30^{+}$lymphoproliferative disorders ( $\mathrm{pcCD} 30^{+}$LPDs) varied from $3 \%$ to $22 \%$ in earlier studies from different geographical areas (Table 4). Among Asian countries, Korea and Taiwan reported a high rate of pcCD30+ LPDs at about 20\% of PCLs, but we found this condition only in 5.1\% of PCLs. According to our study, the prevalence of pcALCL was 3.6\% which was similar to the reports from China and Iran, but it was lower than several reports from Western and Asian countries. Notably, compared with other countries, Korea had considerably higher rate $(11.1 \%)$ of pcALCL. The proportion of patients with pcALCL in our study was higher than LyP, similar to in studies from Japan and Korea. LyP is a self-limiting condition that can mimic many inflammatory dermatoses and other lymphomas, both clinically and histopathologically. In addition, more histologic subtypes of LyP have been established over time, even up to recently [1]. As a result, LyP may be underdiagnosed in some circumstances, such as the lack of experienced dermatopathologists or cutaneous lymphoma experts in the area.

The prevalence of other rare subtypes of PCLs can be significantly different among centers. Regarding extranodal NK/T-cell lymphoma, nasal type (ENKTCL-NT), several authors have indicated a higher frequency of this condition in Asian countries compared to in Western countries and a strong association between Epstein-Barr virus (EBV) and ENKTCL in Asian populations [33-35]. However, we found only 1 case $(0.7 \%)$ of ENKTCL-NT in our study, which was lower than reported in other Asian countries [8-10, 36]. In our center experience, many patients with ENKTCL-NT present with extracutaneous manifestations, this can be the explanation of a low rate of primary cutaneous ENKTCL-NT. After a thorough review, we also observed differences in the proportions of ENKTCL-NT, even among studies from the same country. For example, in 2 previous studies from Korea, the incidence of ENKTCL-NT was $16.7 \%$ of PCL patients in a study by Park et al. [27] yet $5.4 \%$ in another study by Lee et al. [9]. From this point of view, we believe that multiple factors play a role in the pathogenesis of various subtypes of PCLs, besides genetics, ethnicity, and geographical areas.

Notably, Japan has a high prevalence of adult T-cell leukemia/lymphoma (ATLL) compared with other countries or regions, including Asian countries, because it is an endemic area of human T-cell lymphotropic virus type 1 (HTLV-1), the virus that causes ATLL $[8,37]$. In contrast, the prevalence of HTLV-1 infection in Thailand is extremely low, which could explain the absence of patients with ATLL in this study [38].

In our study, CBCLs were much rarer (2.2\%), and the pattern of CBCL subtypes was somewhat different, compared to previous studies. pcDLBCL-LT was the most common subtype of CBCLs in the present study, similar to that found in some earlier studies in Asia and the United States; whereas in Europe, pcFCL and pcMZL are more common (Table 4). Several authors discovered an association between pcMZL in Europe and Borrelia burgdorferi infection or Lyme disease $[39,40]$. Thailand is not an endemic area of Lyme disease, and there are no tick species that are Borrelia vectors found in this region [41]. Besides, pathologists occasionally experience challenges to distinguish pcMZL from cutaneous lymphoid hyperplasia (B-cell pseudolymphoma), despite the available immunohistochemical markers [42]. These could be the explanations for the low frequency of CBCLs and the absence of pcMZL in the present study.

The limitations of our study were a single-center retrospective study design and the lack of review in histopathology, although we excluded cases in which pathologists at our hospital did not confirm the diagnosis.

\section{Conclusions}

In conclusion, this is the first study to evaluate the frequency, demographic data, and clinical characteristics of different subtypes of PCLs in Thailand. We reported a high ratio of CTCLs, especially MF and SPTCL, with a female predominance and younger age of patients. The majority of $\mathrm{MF}$ patients had early-stage disease, and HMF was the most common subtype. Since PCLs are rare in the Thai population, a national PCLs registry in Thailand is our future goal.

\section{Data Availability}

The data used to support the findings of this study included within the article. 


\section{Conflicts of Interest}

The authors declare that there is no conflict of interest regarding the publication of this paper.

\section{References}

[1] R. Willemze, L. Cerroni, W. Kempf et al., "The 2018 update of the WHO-EORTC classification for primary cutaneous lymphomas," Blood, vol. 133, no. 16, pp. 1703-1714, 2019.

[2] F. D. Groves, M. S. Linet, L. B. Travis, and S. S. Devesa, "Cancer surveillance series: non-Hodgkin's lymphoma incidence by histologic subtype in the United States from 1978 through 1995," Journal of the National Cancer Institute, vol. 92, no. 15, pp. 1240-1251, 2000.

[3] M. Maurelli, G. Tessari, C. Colato, D. Schena, and G. Girolomoni, "Incidence and ten-year follow-up of primary cutaneous lymphomas: a single-centre cohort study," European Journal of Dermatology, vol. 28, no. 1, pp. 44-49, 2018.

[4] R. Willemze, E. S. Jaffe, G. Burg et al., "WHO-EORTC classification for cutaneous lymphomas," Blood, vol. 105, no. 10, pp. 3768-3785, 2005.

[5] C. Assaf, S. Gellrich, M. Steinhoff et al., "Cutaneous lymphomas in Germany: an analysis of the Central Cutaneous Lymphoma Registry of the German Society of Dermatology (DDG)," Journal of the German Society of Dermatology, vol. 5, no. 8, pp. 662-668, 2007.

[6] P. T. Bradford, S. S. Devesa, W. F. Anderson, and J. R. Toro, "Cutaneous lymphoma incidence patterns in the United States: a population-based study of 3884 cases," Blood, vol. 113, no. 21, pp. 5064-5073, 2009.

[7] F. M. Ghazawi, E. Netchiporouk, E. Rahme et al., "Comprehensive analysis of cutaneous T-cell lymphoma (CTCL) incidence and mortality in Canada reveals changing trends and geographic clustering for this malignancy," Cancer, vol. 123, no. 18 , pp. 3550-3567, 2017.

[8] T. Hamada and K. Iwatsuki, "Cutaneous lymphoma in Japan: a nationwide study of 1733 patients," The Journal of Dermatology, vol. 41, no. 1, pp. 3-10, 2014.

[9] H. S. Lee, K. S. Suh, D. Y. Lee et al., "Cutaneous lymphoma in Korea: a nationwide retrospective study," Acta DermatoVenereologica, vol. 96, no. 4, pp. 535-539, 2016.

[10] H. Z. Shi, Y. X. Liu, Y. Q. Jiang et al., "Clinical characteristics of primary cutaneous lymphoma: analysis from two centres in China," British Journal of Dermatology, vol. 181, no. 6, pp. 1332-1333, 2019.

[11] E. Olsen, E. Vonderheid, N. Pimpinelli et al., "Revisions to the staging and classification of mycosis fungoides and Sezary syndrome: a proposal of the International Society for Cutaneous Lymphomas (ISCL) and the cutaneous lymphoma task force of the European Organization of Research and Treatment of Cancer (EORTC)," Blood, vol. 110, no. 6, pp. 1713-1722, 2007.

[12] E. A. Olsen, S. Whittaker, Y. H. Kim et al., "Clinical end points and response criteria in mycosis fungoides and Sézary syndrome: a consensus statement of the International Society for Cutaneous Lymphomas, the United States Cutaneous Lymphoma Consortium, and the Cutaneous Lymphoma Task Force of the European Organisation for Research and Treatment of Cancer," Journal of Clinical Oncology, vol. 29, no. 18, pp. 2598-2607, 2011.

[13] S. Sukpanichnant, D. Sonakul, A. Piankijagum et al., "Malignant lymphoma in Thailand: changes in the frequency of malignant lymphoma determined from a histopathologic and immunophenotypic analysis of 425 cases at Siriraj hospital," Cancer, vol. 83, no. 6, pp. 1197-1204, 1998.

[14] J. Eder, A. Kern, J. Moser, M. Kitzwogerer, R. Sedivy, and F. Trautinger, "Frequency of primary cutaneous lymphoma variants in Austria: retrospective data from a dermatology referral centre between 2006 and 2013," Journal of the European Academy of Dermatology and Venereology, vol. 29, no. 8, pp. 1517-1523, 2015.

[15] D. Jenni, M. B. Karpova, B. Seifert et al., "Primary cutaneous lymphoma: two-decade comparison in a population of 263 cases from a Swiss tertiary referral centre," British Journal of Dermatology, vol. 164, no. 5, pp. 1071-1077, 2011.

[16] A. Abeldaño, P. Enz, M. Maskin et al., "Primary cutaneous lymphoma in Argentina: a report of a nationwide study of 416 patients," International Journal of Dermatology, vol. 58, no. 4, pp. 449-455, 2019.

[17] F. F. Naeini, B. Abtahi-Naeini, M. Pourazizi, H. Sadeghiyan, and J. Najafian, "Primary cutaneous lymphomas: a clinical and histological study of 99 cases in Isfahan, Iran," Journal of Research in Medical Sciences, vol. 20, no. 9, pp. 827-831, 2015.

[18] C.-N. Lee, C.-K. Hsu, K.-C. Chang, C.-L. Wu, T.-Y. Chen, and J. Y.-Y. Lee, "Cutaneous lymphomas in Taiwan: a review of 118 cases from a medical center in southern Taiwan," Dermatologica Sinica, vol. 36, no. 1, pp. 16-24, 2018.

[19] H. S. Zackheim, S. Amin, M. Kashani-Sabet, and A. McMillan, "Prognosis in cutaneous T-cell lymphoma by skin stage: longterm survival in 489 patients," Journal of the American Academy of Dermatology, vol. 40, no. 3, pp. 418-425, 1999.

[20] R. van Doorn, C. W. Van Haselen, P. C. van Voorst Vader et al., "Mycosis fungoides: disease evolution and prognosis of 309 Dutch patients," Archives of Dermatology, vol. 136, no. 4, pp. 504-510, 2000.

[21] Y. H. Kim, H. L. Liu, S. Mraz-Gernhard, A. Varghese, and R. T. Hoppe, "Long-term outcome of 525 patients with mycosis fungoides and Sezary syndrome: clinical prognostic factors and risk for disease progression," Archives of Dermatology, vol. 139, no. 7, pp. 857-866, 2003.

[22] L. D. Wilson, G. A. Hinds, and J. B. Yu, "Age, race, sex, stage, and incidence of cutaneous lymphoma," Clinical Lymphoma, Myeloma and Leukemia, vol. 12, no. 5, pp. 291-296, 2012.

[23] E. S. T. Tan, M. B. Y. Tang, and S. H. Tan, "Retrospective 5-year review of 131 patients with mycosis fungoides and Sézary syndrome seen at the National Skin Centre, Singapore," Australasian Journal of Dermatology, vol. 47, no. 4, pp. 248-252, 2006.

[24] H. L. J. Lim, E. S. T. Tan, S. I. Tee et al., "Epidemiology and prognostic factors for mycosis fungoides and Sézary syndrome in a multi-ethnic Asian cohort: a 12-year review," Journal of the European Academy of Dermatology and Venereology, vol. 33, no. 8, pp. 1513-1521, 2019.

[25] F. C. Furlan and J. A. Sanches, "Hypopigmented mycosis fungoides: a review of its clinical features and pathophysiology," Anais Brasileiros de Dermatologia, vol. 88, no. 6, pp. 954960, 2013.

[26] R. Willemze, P. M. Jansen, L. Cerroni et al., "Subcutaneous panniculitis-like T-cell lymphoma: definition, classification, and prognostic factors: an EORTC Cutaneous Lymphoma Group Study of 83 cases," Blood, vol. 111, no. 2, pp. 838-845, 2008.

[27] J. H. Park, H. T. Shin, D. Y. Lee et al., "World Health Organization-European Organization for Research and 
Treatment of Cancer classification of cutaneous lymphoma in Korea: a retrospective study at a single tertiary institution," Journal of the American Academy of Dermatology, vol. 67, no. 6, pp. 1200-1209, 2012

[28] T. Pongpruttipan, P. Pongtongcharoen, and S. Sukpanichnant, "Mature T-cell and NK-cell lymphomas in Thailand: an analysis of 71 cases," Journal of the Medical Association of Thailand, vol. 94, no. 6, pp. 743-748, 2011.

[29] S. Rutnin, S. Porntharukcharoen, and P. Boonsakan, "Clinicopathologic, immunophenotypic, and molecular analysis of subcutaneous panniculitis-like T-cell lymphoma: a retrospective study in a tertiary care center," Journal of Cutaneous Pathology, vol. 46, no. 1, pp. 44-51, 2019.

[30] M. Ohtsuka, T. Miura, and T. Yamamoto, "Clinical characteristics, differential diagnosis, and treatment outcome of subcutaneous panniculitis-like T-cell lymphoma: a literature review of published Japanese cases," European Journal of Dermatology, vol. 27, no. 1, pp. 34-41, 2017.

[31] D. W. Lee, J. H. Yang, S. M. Lee et al., "Subcutaneous panniculitis-like T-cell lymphoma: a clinical and pathologic study of 14 korean patients," Annals of Dermatology, vol. 23, no. 3, pp. 329-337, 2011.

[32] I. López-Lerma, Y. Peñate, F. Gallardo et al., "Subcutaneous panniculitis-like T-cell lymphoma: clinical features, therapeutic approach, and outcome in a case series of 16 patients," Journal of the American Academy of Dermatology, vol. 79, no. 5, pp. 892-898, 2018.

[33] M. M. Cheung, J. K. Chan, W. H. Lau et al., "Primary nonHodgkin's lymphoma of the nose and nasopharynx: clinical features, tumor immunophenotype, and treatment outcome in 113 patients," Journal of Clinical Oncology, vol. 16, no. 1, pp. 70-77, 1998.

[34] C. Qin, Y. Huang, Y. Feng, M. Li, N. Guo, and H. Rao, "Clinicopathological features and EBV infection status of lymphoma in children and adolescents in South China: a retrospective study of 662 cases," Diagnostic Pathology, vol. 13, no. 1, 2018.

[35] V. Pillai, M. Tallarico, M. R. Bishop, and M. S. Lim, "Mature Tand NK-cell non-Hodgkin lymphoma in children and young adolescents," British Journal of Haematology, vol. 173, no. 4, pp. 573-581, 2016.

[36] K.-L. Liu, W.-C. Tsai, and C.-H. Lee, "Non-mycosis fungoides cutaneous lymphomas in a referral center in Taiwan: a retrospective case series and literature review," PLoS One, vol. 15, no. 1, article e0228046, 2020.

[37] M. Satake, K. Yamaguchi, and K. Tadokoro, "Current prevalence of HTLV-1 in Japan as determined by screening of blood donors," Journal of Medical Virology, vol. 84, no. 2, pp. 327335, 2012.

[38] S. Oota, K. Chaiwong, S. Pikulsod et al., "Human T-cell lymphotropic virus type I and II seroprevalence among volunteer blood donors in Thailand," Pathogens and Global Health, vol. 112, no. 7, pp. 343-348, 2018.

[39] J. J. Hoefnagel, M. H. Vermeer, P. M. Jansen et al., "Primary cutaneous marginal zone B-cell lymphoma: clinical and therapeutic features in 50 cases," Archives of Dermatology, vol. 141, no. 9, pp. 1139-1145, 2005.

[40] E. Roggero, E. Zucca, C. Mainetti et al., "Eradication of_Borrelia burgdorferi_ infection in primary marginal zone B-cell lymphoma of the skin," Human Pathology, vol. 31, no. 2, pp. 263-268, 2000.
[41] P. Tanskul, H. E. Stark, and I. Inlao, "A checklist of ticks of Thailand (Acari: Metastigmata: Ixodoidea)," Journal of Medical Entomology, vol. 20, no. 3, pp. 330-341, 1983.

[42] M. Lima, "Cutaneous primary B-cell lymphomas: from diagnosis to treatment," Anais Brasileiros de Dermatologia, vol. 90, no. 5, pp. 687-706, 2015. 